\title{
Comprehensive Geno- and Phenotyping in a Complex Pedigree Including Four Different Inherited Retinal Dystrophies
}

\author{
Johannes Birtel ${ }^{1,2, *(\mathbb{D}}$, Martin Gliem ${ }^{1,2,3}$, Kristina Hess ${ }^{1,2}$, Theresa H. Birtel ${ }^{1}$, Frank G. Holz ${ }^{1,2}$, \\ Ulrich Zechner ${ }^{4,5}$, Hanno J. Bolz ${ }^{4,6}$ and Philipp Herrmann ${ }^{1,2}$ \\ 1 Department of Ophthalmology, University of Bonn, 53113 Bonn, Germany; martin.gliem@roche.com (M.G.); \\ Kristina.Hess@ukbonn.de (K.H.); s4thbirt@uni-bonn.de (T.H.B.); Frank.Holz@ukbonn.de (F.G.H.); \\ philipp.herrmann@ukbonn.de (P.H.) \\ 2 Center for Rare Diseases Bonn (ZSEB), University of Bonn, 53113 Bonn, Germany \\ 3 Roche Pharma Research and Early Development, F. Hoffmann-La Roche Ltd., 4070 Basel, Switzerland \\ 4 Senckenberg Centre for Human Genetics, 60314 Frankfurt, Germany; \\ u.zechner@senckenberg-humangenetik.de (U.Z.); h.bolz@senckenberg-humangenetik.de (H.J.B.) \\ 5 Institute of Human Genetics, University Medical Center Mainz, 55131 Mainz, Germany \\ 6 Institute of Human Genetics, University Hospital of Cologne, 50931 Cologne, Germany \\ * Correspondence: johannes.birtel@ukbonn.de; Tel.: +49-228-287-15505
}

Received: 8 December 2019; Accepted: 23 January 2020; Published: 28 January 2020

\begin{abstract}
Inherited retinal dystrophies (IRDs) are characterized by high clinical and genetic heterogeneity. A precise characterization is desirable for diagnosis and has impact on prognosis, patient counseling, and potential therapeutic options. Here, we demonstrate the effectiveness of the combination of in-depth retinal phenotyping and molecular genetic testing in complex pedigrees with different IRDs. Four affected Caucasians and two unaffected relatives were characterized including multimodal retinal imaging, functional testing, and targeted next-generation sequencing. A considerable intrafamilial phenotypic and genotypic heterogeneity was identified. While the parents of the index family presented with rod-cone dystrophy and $A B C A 4$-related retinopathy, their two sons revealed characteristics in the spectrum of incomplete congenital stationary night blindness and ocular albinism, respectively. Molecular testing revealed previously described variants in $R H O, A B C A 4$, and MITF as well as a novel variant in CACNA1F. Identified variants were verified by intrafamilial co-segregation, bioinformatic annotations, and in silico analysis. The coexistence of four independent IRDs caused by distinct mutations and inheritance modes in one pedigree is demonstrated. These findings highlight the complexity of IRDs and underscore the need for the combination of extensive molecular genetic testing and clinical characterization. In addition, a novel variant in the CACNA1F gene is reported associated with incomplete congenital stationary night blindness.
\end{abstract}

Keywords: molecular testing; genotype; phenotype; dystrophy; retina; NGS; retinitis pigmentosa; Stargardt disease; Waardenburg syndrome; congenital stationary night blindness

\section{Introduction}

Inherited retinal dystrophies (IRDs) are a major cause of severe visual impairment and blindness in the working-age population and contribute to a significant reduction of patients' quality of life $[1,2]$. IRDs are characterized by a high clinical and genetic heterogeneity and a broad spectrum of symptoms, including progressive deterioration of visual acuity, reading difficulties, glare, color vision abnormalities, dark vision problems, and visual field defects. 
With the development of novel therapeutic approaches-in particular gene therapy-a precise phenotypic characterization including multimodal retinal imaging as well as the detection of the disease-causing gene are becoming increasingly important [3]. Strengths of multimodal retinal imaging include the ability to detect metabolic and structural changes ahead of funduscopic visibility and to precisely monitor disease progression or potential therapeutic effects over time [3].

The development of high-throughput DNA sequencing methods has made it more feasible to also achieve diagnoses on a molecular level. Targeted Next-Generation Sequencing (NGS) in particular has been proven as an efficient tool and allows IRD differentiation according to their genetic causes in daily practice [4-16]. One strength of NGS is that a large variety of genes associated with IRDs can be studied simultaneously at relatively low cost.

Herein, we demonstrate the potential of combining comprehensive clinical characterizations and molecular genetic testing using targeted NGS in a complex pedigree. Four different phenotypes caused by mutations in independent genes were revealed in one family. Moreover, a novel variant in the CACNA1F gene is reported associated with incomplete congenital stationary night blindness (CSNB).

\section{Materials and Methods}

This retrospective, cross-sectional study was in adherence to the declaration of Helsinki. Institutional review board approval (Ethics Committee, Medical Faculty, University of Bonn) and patients' informed consent were obtained. All subjects were identified in a referral center for rare retinal diseases at the Department of Ophthalmology, University of Bonn, Germany.

A general medical and ocular history was obtained from each patient and a standardized clinical examination was performed. Clinical assessment included standardized anterior segment and dilated fundus examination, best corrected visual acuity (BCVA) testing, and full-field electroretinography (ERG). Retinal imaging consisted of spectral domain optical coherence tomography (OCT), autofluorescence (AF) imaging with blue excitation light (both, Spectralis HRA+OCT, Heidelberg Engineering, Heidelberg, Germany), fundus photography (Visucam, Zeiss, Oberkochen, Germany) and wide-field pseudo-color- and AF fundus imaging (Optos PLC, Dunfermline, United Kingdom).

Genetic testing was performed as described previously. In brief, NGS analysis was performed by target enrichment with IDT $x$ Gen ${ }^{\circledR}$ Inherited Diseases Panel v1.0 (IDT Integrated Technologies, Coralville, IA, USA), sequencing on an Illumina NextSeq 500 system (Illumina, San Diego, CA, USA) and data evaluation with the SeqNext module of the SeqPilot software (JSI Medical Systems, Ettenheim, Germany) [17].

\section{Results}

A summary of patient characteristics including identified mutations and a pedigree are provided in Table 1; Table 2 and Figure 1, respectively. The Caucasian family initially presented for an ophthalmological examination of their older son (V.1). Family history showed that other family members also revealed inherited retinal diseases that differed from each other and were not comprehensively characterized. Phenotypic similarities between the two sons (V.1, V.2) initially suggested the same genetic disease entity with different severity. However, molecular testing identified independent disease causes. 


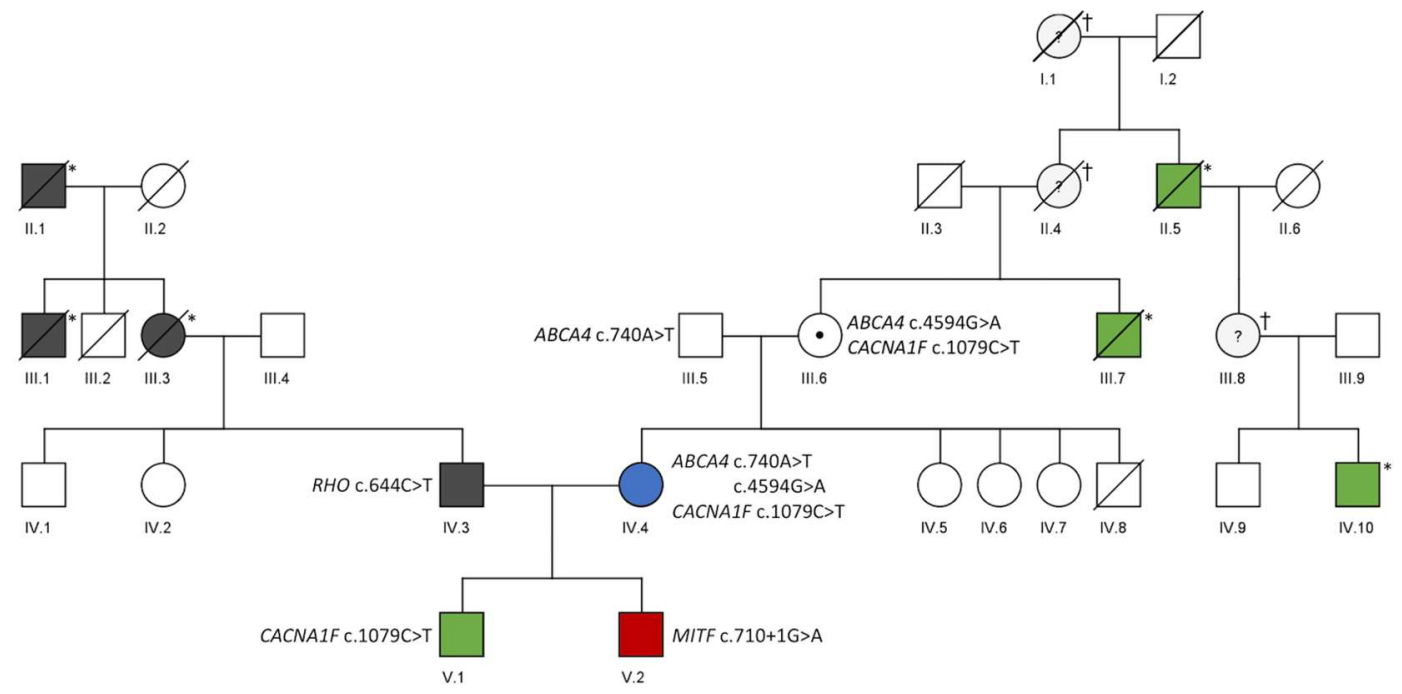

Figure 1. Genetic data of a pedigree including four different inherited retinal dystrophies. Patients with pathological findings are indicated by filled symbols. Black: RHO-related retinopathy. Green: $C A C N A 1 F$-related retinopathy. Red: MITF-related retinopathy. Blue: ABCA4-related retinopathy. For individuals who underwent genetic testing, the identified variants are given next to the individual's symbol. *: affected based on family history, + : assumed carrier of CACNA1Fvariant.

The 48-year-old father (IV.3) reported dark adaptation problems since childhood and visual field defects starting in his second decade. At the age of 18 , he was diagnosed with retinitis pigmentosa (RP) and a reduction of visual acuity was noted over the last years. Now, BCVA was 20/32 and 20/50 in the right and left eye, respectively. The deceased mother (III.3) of the patient as well as the maternal grandfather (II.1) were also affected by RP (Figure 1). On clinical examination (Figure 2) typical RP characteristics were revealed including bilateral posterior subcapsular cataract, arteriolar attenuation, retinal pigmentary changes, vitreous cells, a paracentral ring of increased AF, reduced AF in the (mid-) peripheral retina, and a cystoid macular edema on OCT imaging. Scotopic and photopic responses on ERG recordings were nearly extinguished. In line with these clinical findings, molecular testing identified a previously described heterozygous pathogenic missense variant (c.644C > T, p.Pro215Leu, Table 1; Table 2) in the RHO gene (NCBI Reference Sequence NM_000539.3) [18].

The 45-year-old mother (IV.4) reported reduced visual acuity and reading problems starting at the age of 15 . One year later, she was diagnosed with macular dystrophy and over the last decades, she experienced a slow deterioration of visual acuity as well as pronounced glare and dark adaptation problems. At presentation, BCVA was hand movements in both eyes. Scotopic and photopic responses on ERG recordings were reduced. Ophthalmoscopy and retinal imaging revealed features of $A B C A 4$-related retinopathy including pronounced bilateral chorioretinal atrophy, pigmentary alterations as well as abnormally in- and decreased AF surrounding the area of atrophy (Figure 2). Molecular testing identified two previously described causative heterozygous missense variants (c.740A > T, c.4594G $>$ A, Table 1; Table 2) in the ABCA4 gene (NCBI Reference Sequence NM_000350.3) in compound heterozygous state (confirmed by segregation analysis of her parents III.5 and III.6) [19-21]. 

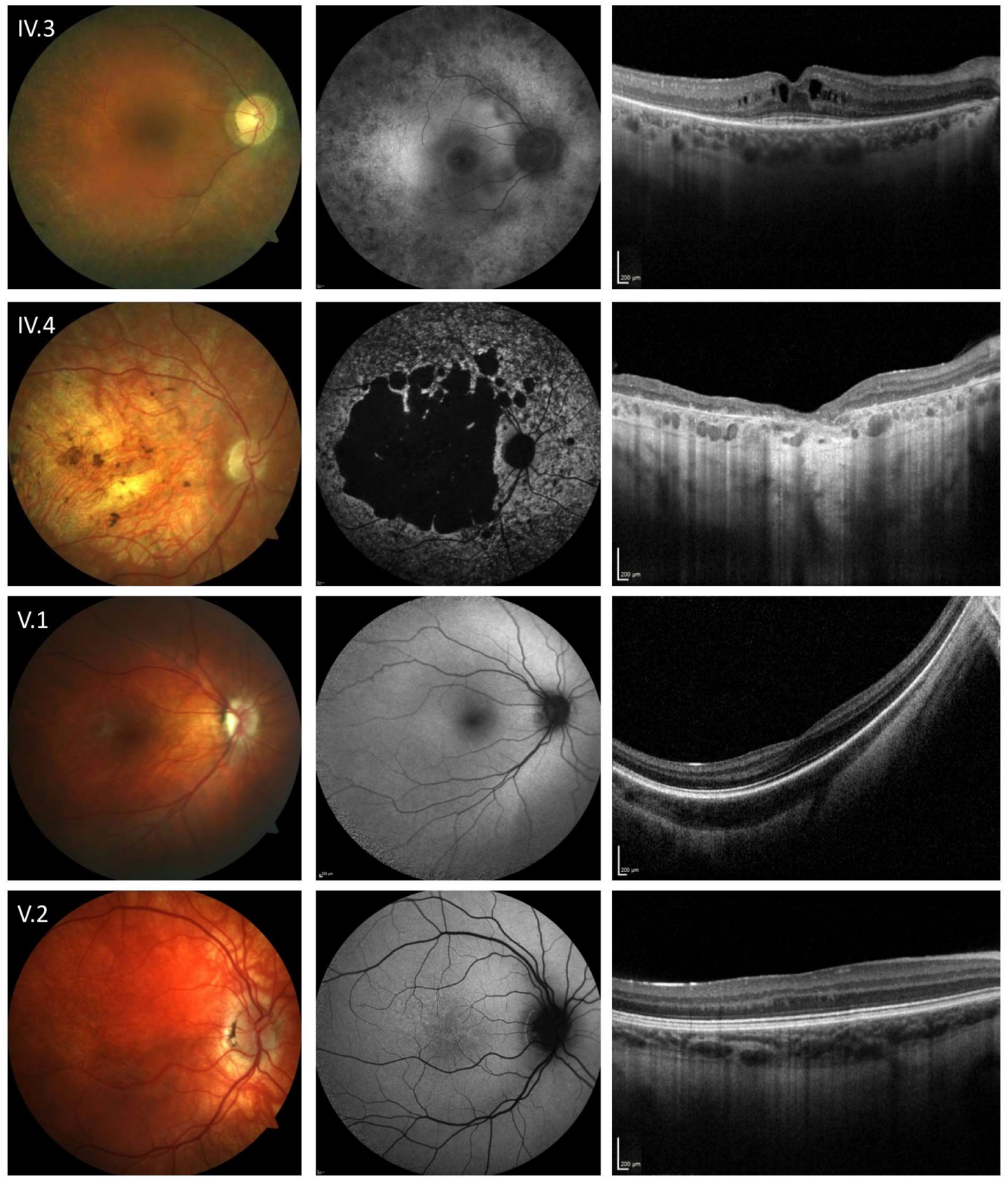

Figure 2. Retinal phenotype associated with mutations in the RHO (IV.3), ABCA4 (IV.4), CACNA1F (V.1) and MITF (V.2) gene. Fundus color image (first column), fundus autofluorescence imaging with $488 \mathrm{~nm}$ excitation light (second column), and horizontal spectral-domain optical coherence tomography line scan (third column) are shown. Patient numbers refer to Figure 1. Only one eye is shown due to high symmetry between eyes.

The 13-year-old son (V.1) reported reduced visual acuity, reading problems, dark adaptation problems, photophobia since childhood, and no color vision problems. Horizontal nystagmus was present since the first weeks of life and visual acuity was described as stable since childhood. At presentation, BCVA was 20/200 and 20/80 in the right and left eye, respectively. Ophthalmoscopy revealed a nearly unremarkable fundus with only minor granular alterations and on OCT imaging foveal hypoplasia was noted (Figure 2). Electronegative scotopic responses with a reduced but measurable b-wave were identified on ERG. Clinical differential diagnosis included ocular albinism, achromatopsia, and CSNB and the latter was supported by the identification of a novel hemizygous missense variant 
(c.1079C >T, Table 1) in the CACNA1F gene (NCBI Reference Sequence NM_005183.4) resulting in an amino acid exchange at an evolutionarily highly conserved position (p.(Ser360Phe)) in the $\alpha_{1 \mathrm{~F}}$ subunit of the $\mathrm{Ca}_{\mathrm{v}} 1.4$ calcium channel. In silico assessment using eight algorithms (DANN, FATHMM, FATHMM-MKL, LRT, MutationAssessor, MutationTaster, PROVEAN and SIFT [17]) predicted the variant to be pathogenic and affect the channel function in a deleterious way (Table 2). The variant has not been described in previous reports nor in clinical (HGMD, ClinVar, LOVD) or population (gnomAD Ex.) variant databases (Table 2). No further disease-relevant variants or CNVs were detected in currently known IRD-associated genes. Segregation analysis identified the mother (IV.4) as carrier for this variant. After the genetic test result was discussed with the family, the mother (IV.4) disclosed that her maternal uncle (III.7), granduncle (II.5) and a grandson (IV.10) of this granduncle also manifested symptoms in the spectrum of incomplete CSNB including nystagmus and non-progressive reduced visual acuity. However, they were deceased or not available for clinical examination or segregation analysis.

The 11-year-old son (V.2) reported reduced visual acuity, reading problems, and glare since childhood but no dark adaptation problems. At presentation, BCVA was 20/50 and 20/40 in the right and left eye, respectively. Ophthalmic examination and retinal imaging revealed microstrabism, iris heterochromia, iris translucence, fundus hypopigmentation with central granular alterations, and foveal hypoplasia (Figure 2). On ERG electronegative scotopic responses were identified. Furthermore, congenital sensorineural deafness, treated with cochlear implants, was reported. No further family members reported hearing problems. These clinical findings also pointed to the spectrum of ocular albinism, achromatopsia or CSNB. Molecular testing revealed a previously described, heterozygous pathogenic variant (c.710+1G>A, Table 1) in the MITF gene (NCBI Reference Sequence NM_000248.3) that has been associated with autosomal dominant Waardenburg syndrome [22]. This variant alters the consensus donor splice site sequence of intron 7 of the MITF gene. In silico assessment using six prediction algorithms (DANN, FATHMM-MKL, MutationTaster, Human Splicing Finder, Splice Site Prediction by Neural Network and varSEAK Online splice prediction tool [17]) predicted the variant to be a pathogenic null variant (Table 2). Another variant (c.710+1G>T) at the same base position has been also described as a pathogenic variant in patients with Waardenburg syndrome [23]. Segregation analysis indicated that the variant most probably occurred de novo in the patient. In the NGS analysis of currently known IRD-associated genes, no other disease-relevant variants or CNVs were detected. 
Table 1. Patient Characteristics.

\begin{tabular}{|c|c|c|c|c|c|c|c|c|c|c|c|}
\hline ID & Age & Gender & $\begin{array}{l}\text { Refraction [dpt] } \\
(\mathrm{sph} / \mathrm{cyl})\end{array}$ & $\begin{array}{l}\text { OD } \\
\text { OS }\end{array}$ & ODOS & Gene & Zygosity & $\begin{array}{l}\text { Exons/ } \\
\text { Introns }\end{array}$ & Nucleotide & Protein & Reference \\
\hline IV.3 & 48 & $\mathrm{~m}$ & $\begin{array}{l}-0.75 /-2.25 \\
-0.75 /-1.00\end{array}$ & & $\begin{array}{l}20 / 32 \\
20 / 50\end{array}$ & RHO & het & Exon 3 & c. $644 \mathrm{C}>\mathrm{T}$ & p.Pro215Leu & [18] \\
\hline \multirow{3}{*}{ IV.4 } & \multirow{3}{*}{45} & \multirow{3}{*}{$f$} & \multirow{3}{*}{$\begin{array}{l}+3.00 /-2.25 \\
+3.25 /-2.50\end{array}$} & & \multirow{3}{*}{$\begin{array}{l}\mathrm{HM} \\
\mathrm{HM}\end{array}$} & \multirow{2}{*}{$A B C A 4$} & het & Exon 6 & c. $740 \mathrm{~A}>\mathrm{T}$ & p.(Asn247Ile) & [19] \\
\hline & & & & & & & het & Exon 31 & c. $4594 \mathrm{G}>\mathrm{A}$ & p.(Asp1532Asn) & {$[20,21]$} \\
\hline & & & & & & CACNA1F & het & Exon 8 & c. $1079 \mathrm{C}>\mathrm{T}$ & p.(Ser360Phe) & novel \\
\hline V.1 & 13 & $\mathrm{~m}$ & $\begin{array}{l}-1.75 /-4.25 \\
-2.75 /-3.25\end{array}$ & & $\begin{array}{l}20 / 50 \\
20 / 40\end{array}$ & CACNA1F & hem & Exon 8 & c. $1079 \mathrm{C}>\mathrm{T}$ & p.(Ser360Phe) & novel \\
\hline V.2 & 11 & $\mathrm{~m}$ & $\begin{array}{l}+4.50 /-0.50 \\
+6.00 /-1.25\end{array}$ & & $\begin{array}{c}20 / 200 \\
20 / 80\end{array}$ & MITF & het & Exon 7 & c. $710+1 G>A$ & splice site & [22] \\
\hline
\end{tabular}

f: female, m: male, OD: right eye, OS: left eye, BCVA: best corrected visual acuity, HM: hand motion, het: heterozygous, hem: hemizygous.

Table 2. Minor allele frequencies and pathogenicity scores of the identified variants.

\begin{tabular}{|c|c|c|c|c|c|c|c|c|c|c|c|c|c|c|}
\hline ID & Gene & $\begin{array}{l}\text { Nucleotide } \\
\text { Change }\end{array}$ & Protein Change & $\begin{array}{c}\text { MAF } \\
\text { (GnomADEx.) }\end{array}$ & DANN & FATHMM & FATHMM-MKL & LRT & $\begin{array}{l}\text { Mutation } \\
\text { Assessor }\end{array}$ & $\begin{array}{c}\text { Mutation } \\
\text { Taster }\end{array}$ & PROVEAN & SIFT & $\begin{array}{c}\text { HSF, } \\
\text { SSPNN, } \\
\text { varSEAK } \\
\text { Online }\end{array}$ & Reference \\
\hline IV.3 & RHO & c. $644 \mathrm{C}>\mathrm{T}$ & p.Pro215Leu & absent & 0.9989 & Tolerated & Damaging & Deleterious & High & $\begin{array}{l}\text { Disease } \\
\text { causing }\end{array}$ & Damaging & Damaging & & [18] \\
\hline \multirow{2}{*}{ IV.4 } & \multirow{2}{*}{$A B C A 4$} & c. $740 \mathrm{~A}>\mathrm{T}$ & p.(Asn247lle) & absent & 0.9905 & Damaging & Damaging & Neutral & Medium & $\begin{array}{l}\text { Disease } \\
\text { causing }\end{array}$ & Damaging & Damaging & - & [19] \\
\hline & & c. $4594 \mathrm{G}>\mathrm{A}$ & p.(Asp1532Asn) & 0.000107 & 0.9993 & Damaging & Damaging & Deleterious & Medium & $\begin{array}{l}\text { Disease } \\
\text { causing }\end{array}$ & Damaging & Damaging & - & {$[20,21]$} \\
\hline IV.4, V.1 & CACNA1F & c. $1079 \mathrm{C}>\mathrm{T}$ & p.(Ser360Phe) & absent & 0.9953 & Damaging & Damaging & Deleterious & Medium & $\begin{array}{l}\text { Disease } \\
\text { causing }\end{array}$ & Damaging & Damaging & - & novel \\
\hline V.2 & MITF & c. $710+1 \mathrm{G}>\mathrm{A}$ & p.? & absent & 0.9956 & - & Damaging & - & - & $\begin{array}{l}\text { Disease } \\
\text { causing }\end{array}$ & - & - & $\begin{array}{c}\text { LOF of } \\
\text { donor } \\
\text { splice site }\end{array}$ & [22] \\
\hline
\end{tabular}




\section{Discussion}

Inherited retinal dystrophies are clinically and genetically heterogeneous diseases with currently more than 250 associated genes (RetNet, https://sph.uth.edu/retnet). In this report, we demonstrate that the combination of high-resolution retinal imaging, clinical, and functional examinations, as well as molecular testing is highly effective to characterize families with complex pedigrees including different IRDs and inheritance modes. This included the identification of a novel variant in the CACNA1F gene and previously described mutations in the RHO, ABCA4, and MITF genes.

While the diagnoses of the two unrelated parents (IV.3, IV.4), with autosomal dominant RP and autosomal recessive $A B C A 4$-related retinopathy, respectively, were straight forward, the different molecular genetic findings of the two children (V.1, V.2) were rather unexpected. Both sons displayed characteristics seen in the phenotypic spectrum of ocular albinism, achromatopsia, CSNB even though distinct differences were identified. A conclusive disease classification was challenging at the time of the presentation and molecular genetic testing was required for precise disease classification. The phenotypes were in line with the molecular genetic findings and included independent retinal dystrophies with autosomal dominant de novo and X-linked variants, respectively.

Mutations in the RHO gene, encoding for rhodopsin, the visual pigment initiating the phototransduction cascade in rod photoreceptors, are among the major causes for autosomal-dominant RP [12,24-27]. The known phenotypic variability, with some mutations leading to a diffuse rod-cone dysfunction while others cause a rather restricted phenotype primarily affecting the inferior hemisphere of the retina, has been associated with variable allelic expressivity $[28,29]$.

$A B C A 4$-related retinopathy, one of the most common monogenic causes for retinal degeneration, is known for a broad phenotypic spectrum, ranging from mild Stargardt disease to severe cone-rod dystrophy [11,30]. It is caused by biallelic mutations in the ATP-binding cassette sub-family A member 4 $(A B C A 4)$ gene [31]. Dysfunction or loss of function of the encoded protein product leads to excessive accumulation of visual cycle end-products such as lipofuscin in the retinal pigment epithelium (RPE), and eventually RPE and photoreceptor atrophy with associated vision loss [32-35].

Mutations in the X-linked CACNA1F gene, encoding a $\alpha 1$-subunit of a voltage-gated L-type calcium channel expressed in the photoreceptor synapses, in most cases lead to incomplete CSNB [36-38]. Each $\alpha 1$-subunit contains four repeat domains with six transmembrane helical domains [37]. The novel CACNA1F variant identified in this report results in an amino acid exchange (p.(Ser360Phe)) at an evolutionarily highly conserved position and is predicted to be pathogenic by all applied in silico algorithms. Taking these findings and the clinical diagnosis of incomplete CSNB into account, it is likely that this novel variant represents a disease-causing mutation.

Mutations in the MITF gene, encoding the Microphthalmia-associated transcription factor which plays an important role in the regulation of tyrosinase, a key enzyme for melanogenesis and melanocyte differentiation, are known to cause Waardenburg syndrome type 2A (WS2) and Tietz albinism-deafness syndrome (TS), two overlapping disorders [39-44]. While non-truncating mutations in the MITF basic domain lead to TS, encompassing more generalized effects including albinoid-like hypopigmentation of the skin, hair, iris and severe hearing loss, other mutations in the MITF gene cause WS2 characterized by patchy depigmentation and uni- or bilateral deafness $[43,45]$. The presented patient with patchy pigmentations, iris heterochromia and a predicted null variant was assigned to the spectrum of WS2.

\section{Conclusions}

In summary, we demonstrate the coexistence of four different IRDs caused by distinct mutations and inheritance modes in one family. We reinforce the complexity of IRDs and highlight the need for the combination of extensive molecular diagnostic and clinical characterization. A precise characterization may not only help to identify the correct diagnosis with a clear prognosis, but it also supports patient counseling and may have implications in view of future therapeutic options. In addition, we report a novel variant in the CACNA1F gene associated with incomplete CSNB. 
Author Contributions: Conceptualization: J.B., U.Z., P.H.; formal analysis: J.B., U.Z., H.J.B.; investigation: J.B., M.G., K.H., T.H.B., F.G.H., U.Z., H.J.B., P.H.; methodology: J.B., U.Z., H.J.B.; project administration: J.B.; visualization: J.B., U.Z.; writing—original draft: J.B., U.Z.; writing—review and editing: M.G., K.H., T.H.B., F.G.H., H.J.B., P.H. All authors have read and agreed to the published version of the manuscript.

Funding: This work was supported by the "EYEnovative" research award (Novartis Pharma GmbH, Germany) to JB and by the German Research Foundation (DFG, grant \# GL920/1-1) to MG. The funding organizations had no role in the design and conduct of the study; collection, management, analysis, and interpretation of the data; preparation, review, or approval of the manuscript; and decision to submit the manuscript for publication. The authors alone are responsible for the content and writing of the paper.

Conflicts of Interest: M.G. is employee and equity owner of F. Hoffmann-La Roche Ltd., Basel, Switzerland. The other authors report no conflict of interest.

\section{References}

1. Finger, R.P.; Fimmers, R.; Holz, F.G.; Scholl, H.P. Prevalence and causes of registered blindness in the largest federal state of Germany. Br. J. Ophthalmol. 2011, 95, 1061-1067. [CrossRef]

2. Krumpaszky, H.G.; Ludtke, R.; Mickler, A.; Klauss, V.; Selbmann, H.K. Blindness incidence in Germany. A population-based study from Wurttemberg-Hohenzollern. Ophthalmologica 1999, 213, 176-182. [CrossRef] [PubMed]

3. Birtel, J.; Gliem, M.; Holz, F.G.; Herrmann, P. Imaging and molecular genetic diagnostics for the characterization of retinal dystrophies. Ophthalmologe 2018, 115, 1021-1027. [CrossRef] [PubMed]

4. Eisenberger, T.; Neuhaus, C.; Khan, A.O.; Decker, C.; Preising, M.N.; Friedburg, C.; Bieg, A.; Gliem, M.; Charbel Issa, P.; Holz, F.G.; et al. Increasing the yield in targeted next-generation sequencing by implicating $\mathrm{CNV}$ analysis, non-coding exons and the overall variant load: The example of retinal dystrophies. PLoS ONE 2013, 8, e78496. [CrossRef] [PubMed]

5. Bolz, H.J. Genetic diagnostics of retinal dystrophies: Breakthrough with new methods of DNA sequencing. Ophthalmologe 2018, 115, 1028-1034. [CrossRef]

6. Shanks, M.E.; Downes, S.M.; Copley, R.R.; Lise, S.; Broxholme, J.; Hudspith, K.A.; Kwasniewska, A.; Davies, W.I.; Hankins, M.W.; Packham, E.R.; et al. Next-generation sequencing (NGS) as a diagnostic tool for retinal degeneration reveals a much higher detection rate in early-onset disease. Eur. J. Hum. Genet. 2013, 21, 274-280. [CrossRef]

7. Glockle, N.; Kohl, S.; Mohr, J.; Scheurenbrand, T.; Sprecher, A.; Weisschuh, N.; Bernd, A.; Rudolph, G.; Schubach, M.; Poloschek, C.; et al. Panel-based next generation sequencing as a reliable and efficient technique to detect mutations in unselected patients with retinal dystrophies. Eur. J. Hum. Genet. 2014, 22, 99-104. [CrossRef]

8. Oishi, M.; Oishi, A.; Gotoh, N.; Ogino, K.; Higasa, K.; Iida, K.; Makiyama, Y.; Morooka, S.; Matsuda, F.; Yoshimura, N. Next-generation sequencing-based comprehensive molecular analysis of 43 Japanese patients with cone and cone-rod dystrophies. Mol. Vis. 2016, 22, 150-160.

9. Birtel, J.; Gliem, M.; Mangold, E.; Tebbe, L.; Spier, I.; Muller, P.L.; Holz, F.G.; Neuhaus, C.; Wolfrum, U.; Bolz, H.J.; et al. Novel Insights Into the Phenotypical Spectrum of KIF11-Associated Retinopathy, Including a New Form of Retinal Ciliopathy. Invest. Ophthalmol. Vis. Sci. 2017, 58, 3950-3959. [CrossRef]

10. Bravo-Gil, N.; Gonzalez-Del Pozo, M.; Martin-Sanchez, M.; Mendez-Vidal, C.; Rodriguez-de la Rua, E.; Borrego, S.; Antinolo, G. Unravelling the genetic basis of simplex Retinitis Pigmentosa cases. Sci. Rep. 2017, 7, 41937. [CrossRef]

11. Birtel, J.; Gliem, M.; Oishi, A.; Müller, P.L.; Herrmann, P.; Holz, F.G.; Mangold, E.; Knapp, M.; Bolz, H.J.; Charbel Issa, P. Genetic testing in patients with retinitis pigmentosa-Features of unsolved cases. Clin. Exp. Ophthalmol. 2019, 47, 779-786. [CrossRef] [PubMed]

12. Birtel, J.; Eisenberger, T.; Gliem, M.; Muller, P.L.; Herrmann, P.; Betz, C.; Zahnleiter, D.; Neuhaus, C.; Lenzner, S.; Holz, F.G.; et al. Clinical and genetic characteristics of 251 consecutive patients with macular and cone/cone-rod dystrophy. Sci. Rep. 2018, 8, 4824. [CrossRef] [PubMed]

13. Birtel, J.; Gliem, M.; Mangold, E.; Muller, P.L.; Holz, F.G.; Neuhaus, C.; Lenzner, S.; Zahnleiter, D.; Betz, C.; Eisenberger, T.; et al. Next-generation sequencing identifies unexpected genotype-phenotype correlations in patients with retinitis pigmentosa. PLoS ONE 2018, 13, e0207958. [CrossRef] [PubMed] 
14. Yusuf, I.H.; Birtel, J.; Shanks, M.E.; Clouston, P.; Downes, S.M.; Charbel Issa, P.; MacLaren, R.E. Clinical Characterization of Retinitis Pigmentosa Associated with Variants in SNRNP200. JAMA Ophthalmol. 2019, in press. [CrossRef]

15. De Castro-Miro, M.; Tonda, R.; Marfany, G.; Casaroli-Marano, R.P.; Gonzalez-Duarte, R. Novel mutation in the choroideremia gene and multi-Mendelian phenotypes in Spanish families. Br. J. Ophthalmol. 2018, 102, 1378-1386. [CrossRef]

16. Cehajic-Kapetanovic, J.; Birtel, J.; McClements, M.E.; Shanks, M.E.; Clouston, P.; Downes, S.M.; Charbel Issa, P.; MacLaren, R.E. Clinical and Molecular Characterization of PROM1-Related Retinal Degeneration. JAMA Netw Open 2019, 2, e195752. [CrossRef]

17. Preising, M.N.; Gorg, B.; Friedburg, C.; Qvartskhava, N.; Budde, B.S.; Bonus, M.; Toliat, M.R.; Pfleger, C.; Altmuller, J.; Herebian, D.; et al. Biallelic mutation of human SLC6A6 encoding the taurine transporter TAUT is linked to early retinal degeneration. FASEB J. 2019, 33, 11507-11527. [CrossRef]

18. Martinez-Gimeno, M.; Trujillo, M.J.; Lorda, I.; Gimenez, A.; Calvo, M.T.; Ayuso, C.; Carballo, M. Three novel mutations (P215L, T289P, and 3811-2 A-> G) in the rhodopsin gene in autosomal dominant retinitis pigmentosa in Spanish families. Hum. Mutat. 2000, 16, 95-96. [CrossRef]

19. Jaakson, K.; Zernant, J.; Kulm, M.; Hutchinson, A.; Tonisson, N.; Glavac, D.; Ravnik-Glavac, M.; Hawlina, M.; Meltzer, M.R.; Caruso, R.C.; et al. Genotyping microarray (gene chip) for the ABCR (ABCA4) gene. Hum. Mutat. 2003, 22, 395-403. [CrossRef]

20. Lewis, R.A.; Shroyer, N.F.; Singh, N.; Allikmets, R.; Hutchinson, A.; Li, Y.; Lupski, J.R.; Leppert, M.; Dean, M. Genotype/Phenotype analysis of a photoreceptor-specific ATP-binding cassette transporter gene, ABCR, in Stargardt disease. Am. J. Hum. Genet. 1999, 64, 422-434. [CrossRef]

21. Cella, W.; Greenstein, V.C.; Zernant-Rajang, J.; Smith, T.R.; Barile, G.; Allikmets, R.; Tsang, S.H. G1961E mutant allele in the Stargardt disease gene ABCA4 causes bull's eye maculopathy. Exp. Eye Res. 2009, 89, 16-24. [CrossRef] [PubMed]

22. Pingault, V.; Ente, D.; Dastot-Le Moal, F.; Goossens, M.; Marlin, S.; Bondurand, N. Review and update of mutations causing Waardenburg syndrome. Hum. Mutat. 2010, 31, 391-406. [CrossRef] [PubMed]

23. Sun, L.; Li, X.; Shi, J.; Pang, X.; Hu, Y.; Wang, X.; Wu, H.; Yang, T. Molecular etiology and genotype-phenotype correlation of Chinese Han deaf patients with type I and type II Waardenburg Syndrome. Sci. Rep. 2016, 6, 35498. [CrossRef] [PubMed]

24. Sullivan, L.S.; Bowne, S.J.; Birch, D.G.; Hughbanks-Wheaton, D.; Heckenlively, J.R.; Lewis, R.A.; Garcia, C.A.; Ruiz, R.S.; Blanton, S.H.; Northrup, H.; et al. Prevalence of disease-causing mutations in families with autosomal dominant retinitis pigmentosa: A screen of known genes in 200 families. Invest. Ophthalmol. Vis. Sci. 2006, 47, 3052-3064. [CrossRef] [PubMed]

25. Daiger, S.P.; Bowne, S.J.; Sullivan, L.S. Genes and Mutations Causing Autosomal Dominant Retinitis Pigmentosa. Cold Spring Harb. Perspect. Med. 2014, 5. [CrossRef] [PubMed]

26. Fernandez-San Jose, P.; Blanco-Kelly, F.; Corton, M.; Trujillo-Tiebas, M.J.; Gimenez, A.; Avila-Fernandez, A.; Garcia-Sandoval, B.; Lopez-Molina, M.I.; Hernan, I.; Carballo, M.; et al. Prevalence of Rhodopsin mutations in autosomal dominant Retinitis Pigmentosa in Spain: Clinical and analytical review in 200 families. Acta Ophthalmol. 2015, 93, e38-e44. [CrossRef]

27. Audo, I.; Manes, G.; Mohand-Said, S.; Friedrich, A.; Lancelot, M.E.; Antonio, A.; Moskova-Doumanova, V.; Poch, O.; Zanlonghi, X.; Hamel, C.P.; et al. Spectrum of rhodopsin mutations in French autosomal dominant rod-cone dystrophy patients. Invest. Ophthalmol. Vis. Sci. 2010, 51, 3687-3700. [CrossRef]

28. Heckenlively, J.R.; Rodriguez, J.A.; Daiger, S.P. Autosomal dominant sectoral retinitis pigmentosa. Two families with transversion mutation in codon 23 of rhodopsin. Arch. Ophthalmol. 1991, 109, 84-91. [CrossRef]

29. Cideciyan, A.V.; Hood, D.C.; Huang, Y.; Banin, E.; Li, Z.Y.; Stone, E.M.; Milam, A.H.; Jacobson, S.G. Disease sequence from mutant rhodopsin allele to rod and cone photoreceptor degeneration in man. Proc. Natl. Acad. Sci. USA 1998, 95, 7103-7108. [CrossRef]

30. Hamel, C.P. Cone rod dystrophies. Orphanet J. Rare Dis. 2007, 2, 7. [CrossRef]

31. Kitiratschky, V.B.; Grau, T.; Bernd, A.; Zrenner, E.; Jagle, H.; Renner, A.B.; Kellner, U.; Rudolph, G.; Jacobson, S.G.; Cideciyan, A.V.; et al. ABCA4 gene analysis in patients with autosomal recessive cone and cone rod dystrophies. Eur. J. Hum. Genet. 2008, 16, 812-819. [CrossRef] [PubMed] 
32. Mata, N.L.; Weng, J.; Travis, G.H. Biosynthesis of a major lipofuscin fluorophore in mice and humans with ABCR-mediated retinal and macular degeneration. Proc. Natl. Acad. Sci. UA 2000, 97, 7154-7159. [CrossRef] [PubMed]

33. Koenekoop, R.K. The gene for Stargardt disease, ABCA4, is a major retinal gene: A mini-review. Ophthalmic Genet. 2003, 24, 75-80. [CrossRef] [PubMed]

34. . Cideciyan, A.V.; Aleman, T.S.; Swider, M.; Schwartz, S.B.; Steinberg, J.D.; Brucker, A.J.; Maguire, A.M.; Bennett, J.; Stone, E.M.; Jacobson, S.G. Mutations in ABCA4 result in accumulation of lipofuscin before slowing of the retinoid cycle: A reappraisal of the human disease sequence. Hum. Mol. Genet. 2004, 13, 525-534. [CrossRef]

35. Duncker, T.; Tsang, S.H.; Lee, W.; Zernant, J.; Allikmets, R.; Delori, F.C.; Sparrow, J.R. Quantitative fundus autofluorescence distinguishes ABCA4-associated and non-ABCA4-associated bull's-eye maculopathy. Ophthalmology 2015, 122, 345-355. [CrossRef]

36. Bech-Hansen, N.T.; Naylor, M.J.; Maybaum, T.A.; Pearce, W.G.; Koop, B.; Fishman, G.A.; Mets, M.; Musarella, M.A.; Boycott, K.M. Loss-of-function mutations in a calcium-channel alpha1-subunit gene in Xp11.23 cause incomplete X-linked congenital stationary night blindness. Nat. Genet. 1998, 19, $264-267$. [CrossRef]

37. Strom, T.M.; Nyakatura, G.; Apfelstedt-Sylla, E.; Hellebrand, H.; Lorenz, B.; Weber, B.H.; Wutz, K.; Gutwillinger, N.; Ruther, K.; Drescher, B.; et al. An L-type calcium-channel gene mutated in incomplete X-linked congenital stationary night blindness. Nat. Genet. 1998, 19, 260-263. [CrossRef]

38. Knoflach, D.; Schicker, K.; Glosmann, M.; Koschak, A. Gain-of-function nature of Cav1.4 L-type calcium channels alters firing properties of mouse retinal ganglion cells. Channels (Austin) 2015, 9, 298-306. [CrossRef]

39. Hou, L.; Pavan, W.J. Transcriptional and signaling regulation in neural crest stem cell-derived melanocyte development: Do all roads lead to Mitf? Cell. Res. 2008, 18, 1163-1176. [CrossRef]

40. Hughes, A.E.; Newton, V.E.; Liu, X.Z.; Read, A.P. A gene for Waardenburg syndrome type 2 maps close to the human homologue of the microphthalmia gene at chromosome 3p12-p14.1. Nat. Genet. 1994, 7, 509-512. [CrossRef]

41. Tachibana, M.; Takeda, K.; Nobukuni, Y.; Urabe, K.; Long, J.E.; Meyers, K.A.; Aaronson, S.A.; Miki, T. Ectopic expression of MITF, a gene for Waardenburg syndrome type 2, converts fibroblasts to cells with melanocyte characteristics. Nat. Genet. 1996, 14, 50-54. [CrossRef] [PubMed]

42. Cortes-Gonzalez, V.; Zenteno, J.C.; Guzman-Sanchez, M.; Giordano-Herrera, V.; Guadarrama-Vallejo, D.; Ruiz-Quintero, N.; Villanueva-Mendoza, C. Tietz/Waardenburg type 2A syndrome associated with posterior microphthalmos in two unrelated patients with novel MITF gene mutations. Am. J. Med. Genet. A 2016, 170, 3294-3297. [CrossRef] [PubMed]

43. Smith, S.D.; Kelley, P.M.; Kenyon, J.B.; Hoover, D. Tietz syndrome (hypopigmentation/deafness) caused by mutation of MITF. J. Med. Genet. 2000, 37, 446-448. [CrossRef] [PubMed]

44. Tietz, W. A syndrome of deaf-mutism associated with albinism showing dominant autosomal inheritance. Am. J. Hum. Genet. 1963, 15, 259-264. [PubMed]

45. Bourneuf, E.; Otz, P.; Pausch, H.; Jagannathan, V.; Michot, P.; Grohs, C.; Piton, G.; Ammermuller, S.; Deloche, M.C.; Fritz, S.; et al. Rapid Discovery of De Novo Deleterious Mutations in Cattle Enhances the Value of Livestock as Model Species. Sci Rep. 2017, 7, 11466. [CrossRef]

(C) 2020 by the authors. Licensee MDPI, Basel, Switzerland. This article is an open access article distributed under the terms and conditions of the Creative Commons Attribution (CC BY) license (http://creativecommons.org/licenses/by/4.0/). 